\title{
DA ALIENAÇÃO PARENTAL
}

Ana Augusta Rodrigues Westin Ebaid. Daniela Cazarotti Rotta

Universidade do Oeste Paulista - UNOESTE, curso de Direito, Presidente Prudente, SP. E-mail: anaaugusta@unoeste.br

\section{RESUMO}

O Presente artigo tem como objetivo fazer uma análise sobre o tema Alienação Parental, estudando seus conceitos, até chegar às suas consequências mais gravosas, que são a apresentação da Síndrome de Alienação Parental, estudada pelo psiquiatra norte-americano Richard Gardner. O trabalho tem por objetivo, demonstrar a relevância do tema a ser estudado sob uma perspectiva teórica e prática. O tema da Alienação Parental vem atraindo a atenção dos estudiosos do Direito, principalmente por tratar-se de um assunto que define novos parâmetros para a interpretação do Direito. Assim, à medida que a sociedade torna-se mais complexa, surgem novas situações que requerem uma cautela maior do Poder Judiciário no que versa a aplicação do Direito. A metodologia constou de levantamento bibliográfico acerca das principais questões jurídicas que versam sobre o assunto. Com a presente pesquisa constatou-se que a existência de comportamentos de alienação parental, podem causar consequências desastrosas no desenvolvimento da criança.

Palavras-chave: Guarda dos filhos, Alienação Parental, Síndrome de Alienação Parental.

\section{PARENTAL ALIENATION}

\begin{abstract}
Article Gift aims to make an analysis on the subject of Parental Alienation, studying their concepts, to reach their more serious consequences, which are the presentation of the Parental Alienation Syndrome, studied by the American psychiatrist Richard Gardner. The study aims to demonstrate the relevance of the subject to be studied from a theoretical and practical perspective. The subject of Parental Alienation has attracted the attention of scholars of law, mainly because it is a subject that sets new parameters for the interpretation of the law. Thus, as society becomes more complex, new situations arise that require greater caution of the judiciary in which addresses the application of the law. The methodology consisted of literature concerning the major legal issues that deal with the subject. With this research it was found that the existence of parental alienation behaviors can cause disastrous consequences in child development .
\end{abstract}

Keywords: Guard of children, Parental alienation, Parental Alienation Syndrome. 


\section{INTRODUÇÃO}

O tema da Alienação Parental representa na atualidade, um dos maiores desafios a serem enfrentados pela sociedade e pelo Estado, por tratar-se de temas que envolvem a questão da proteção integral da criança e do adolescente, a efetivação dos direitos fundamentais, o direito à convivência familiar, plena e saudável, com os pais e com toda a família.

A caracterização da Alienação Parental decorre de uma disputa judicial, em que um dos genitores (alienante) usa de artifícios, para desqualificar ou outro genitor (alienado), com o intuito de se vingar, agindo de forma argilosa, para obter a guarda definitiva dos filhos.

$\mathrm{O}$ assunto é delicado, deve ser tratado com muita atenção e cautela, não apenas por parte do judiciário mas também por toda a sociedade, devido ao aumento de conflitos familiares, envolvendo processos que versam sobre a guarda dos filhos, e principalmente por envolver interesses de menores, que são o futuro da nossa sociedade.

Logo, o objetivo do trabalho é abordar os principais aspectos sobre o tema da Alienação Parental, bem como apresentar as discussões doutrinárias a respeito de tema proposto.

\section{METODOLOGIA}

$\mathrm{O}$ artigo foi embasado em pesquisas bibliográficas, leituras, bem como em leis, resoluções e artigos eletrônicos. Os dados foram examinados com a aplicação do método hipotéticodedutivo, isto é, partindo do geral para o particular e as informações coletadas analisadas e confrontadas de forma dialética.

\section{DISCUSSÃO}

De acordo com a definição legal (Lei 12.318/2010),

Artigo 2o- Considera-se ato de alienação parental a interferência na formação psicológica da criança e do adolescente, promovida por um dos genitores, pelos avós ou pelos que tenham a criança sob sua guarda ou vigilância, para que repudie o genitor ou que cause prejuízo ao estabelecimento ou manutenção deste.

Impedir ou prejudicar a convivência pacífica entre pai e filho, entre mãe e filho, entre avós e netos é uma das formas de Alienação Parental. Verifica-se, assim que a prática da Alienação Parental é danosa para todos, mas os filhos são os mais prejudicados. Todos são vítimas, inclusive o genitor alienador, que muitas vezes não tem consciência do mal que está causando ao o filho que tanto ama. 
Vale dizer-se que os laços familiares são muito importantes para vida afetiva e social e que os filhos precisam sentir esse amor familiar, para se sentirem seguros. A falta de convivência respeitosa entre os filhos, seus pais e familiares podem trazer muitos sofrimentos à criança ou adolescente e consequentemente gerar problemas futuros.

De acordo com a lei específica no 12.318/2010, a Alienação Parental é a rejeição dos próprios filhos a um dos pais, fenômeno provocado, normalmente, pelo guardião que detém a exclusividade da guarda deles.

Além de introduzir a definição legal da alienação parental no ordenamento jurídico, a proposição estabelece um rol exemplificativo de condutas que dificultam o efetivo convívio entre a criança ou adolescente e seu genitor, de forma a não apenas viabilizar o reconhecimento jurídico da conduta de alienação parental, mas sinalizar, claramente, à sociedade que tais atitudes merecem reprimenda estatal.

São comportamentos clássicos do genitor alienador a sua recusa a passar os telefonemas para os filhos, desenvolver atividades durante o horário de visita do outro genitor, apresentar o novo companheiro (a) do outro genitor e dizer que será seu novo pai/mãe, não entregar presentes, cartas ou passar recados à criança/adolescente, impedir o outro genitor de exercer seu direito de visitas, não avisar sobre compromissos importantes que a criança/adolescente tem, tomar decisões a respeito da criança e não consultar o outro genitor. Também, impedir que o outro tenha acesso a informações sobre a escola, saúde do filho, queira culpar o outro pelo o mau comportamento da criança, por manter contato com o outro genitor ou parentes.

A prática da Alienação Parental é reconhecida como uma forma de abuso emocional, que pode causar à criança ou ao adolescente, sérias consequências de ordem psicológica. E nesse sentido, não há dúvida de que também representa abuso, no exercício do poder familiar, de desrespeito aos direitos de personalidade da criança em formação.

De acordo com IBDFam (Instituto Brasileiro de Direito de Família), as consequências de uma criança submetida à alienação parental são drásticas e corrompem todo o seu futuro. De acordo com o Instituto, a criança alienada começa a apresentar algumas características, como isolamento, baixo rendimento escolar, depressão, melancolia, angústias, fugas, rebeldia, regressões, condutas antissociais e culpa.

Em grande parte dos casos, a alienação parental não afeta a pessoa do genitor alienado mas também todos aqueles que o cercam, principalmente os avós, privando a criança do seu necessário convívio com todo o núcleo familiar. 
Para evitar a alienação parental, os pais deveriam ter consciência de seus atos e responsabilidades, pois o que finda é o enlace conjugal, e não o elo entre pais e filhos, posto que filhos necessitam da presença e equilíbrio de ambos os pais. Assim, a paternidade e a maternidade deveriam estar compromissadas com a integridade mental da criança.

É mais comum do que se possa imaginar que crianças/adolescentes se tornam uma moeda de troca dos pais em processo judicial. Com isto, os tribunais começam a perceber a necessidade de separar a figura conjugal da figura parental, gerando, a discussão acerca do cabimento da guarda compartilhada no ordenamento jurídico. Esse novo arranjo familiar atenderá as necessidades que visam à diminuição da prática da Alienação Parental.

A este respeito, Maria Berenice Dias (2009, p. 45), ao analisar o papel da família na atualidade, conclui que:

Agora, porém, se está vivendo uma outra era. Mudou o conceito de família. 0 primado da afetividade na identificação das estruturas familiares levou à valoração do que se chama filiação afetiva. Graças ao tratamento interdisciplinar que vem recebendo o Direito de Família, passou-se a emprestar maior atenção às questões de ordem psíquica, permitindo o reconhecimento da presença de dano afetivo pela ausência de convívio paterno-filial.

O Poder Judiciário não pode abster-se de apreciar casos que envolvam esse tipo de comportamento, tampouco pode haver tolerância desta prática, de modo que haja uma ação de impedir reincidências e prevenir novas incidências.

Verifica-se que a lei no 12.318/10, apresentou um importante impacto, não só na cultura da sociedade mas também na prática jurídica, pois essa lei tem como finalidade precípua inibir a prática da Alienação Parental e sua decorrência com a apresentação da Síndrome de Alienação Parental.

\section{SÍNDROME DA ALIENAÇÃO PARENTAL}

A Síndrome da Alienação Parental (SAP) foi conhecida através dos trabalhos realizados pelo psiquiatra Dr. Richard A. Gardner, professor do Departamento de Psiquiatria Infantil da Universidade Columbia, em Nova York nos EUA em 1985. Do ponto de vista psicológico, esta síndrome é uma forma de abuso emocional cometida por um dos pais contra a criança.

Neste sentido, Jorge Trindade (2004, p.102), observa:

A Síndrome de Alienação Parental é um transtorno psicológico que se caracteriza por um conjunto de sintomas pelos quais um genitor, denominado cônjuge alienador, transforma a consciência de seus filhos, mediante 
diferentes formas e estratégias de atuação, com objetivo de impedir, obstaculizar ou destruir seus vínculos com o outro genitor, denominado cônjuge alienado, sem que existam motivos reais que justifiquem essa condição. Em outras palavras, consiste num processo de programar uma criança para que odeie um de seus genitores sem justificativa, de modo que a própria criança ingressa na trajetória de desmoralização desse mesmo genitor.

Vale ressaltar, que para muitos pesquisadores existe uma linha tênue que distingue a pratica da Alienação Parental com a apresentação da Síndrome da Alienação Parental, embora, ambos os conceitos sejam intimamente ligados, eles não se confundem. Conforme se constata da lição de Douglas Darnall, invocada por Priscila Maria Pereira Corrêa da Fonseca (2009, p. 52):

A síndrome da alienação parental não se confunde, portanto, com a mera alienação parental. Aquela geralmente é decorrente desta, ou seja, a alienação parental é o afastamento do filho de um dos genitores, provocado pelo outro, via de regra, o titular da custódia. A síndrome, por seu turno, diz respeito às seqüelas emocionais e comportamentais de que vem a padecer a criança vítima daquele alija mento. Assim, enquanto a síndrome refere-se à conduta do filho que se recusa terminante e obstinadamente a ter contato com um dos progenitores e que já sofre as mazelas oriundas daquele rompimento, a alienação parental relaciona-se com o processo desencadeado pelo progenitor que intenta arredar o outro genitor da vida do filho. Essa conduta - quando ainda não dá lugar à instalação da síndrome - é reversível e permite - com o concurso de terapia e auxílio do Poder Judiciário - o restabelecimento das relações com o genitor preterido.

Neste contexto, configura-se Alienação Parental, o simples ato de uma das partes desconstruir a imagem do outro genitor, buscando promover o afastamento dos filhos com o genitor alienado. Ao passo que a Síndrome da Alienação Parental (SAP) seria um estágio avançado de uma psicopatologia, pois nesta fase observam-se as alterações emocionais na figura do filho, que apresenta mudança no comportamento em relação ao genitor-alvo, advindo da prática da Alienação Parental.

Afirmam ainda, os estudiosos sobre o assunto que quando a síndrome ainda não se instalou, ou seja, quando se tem apenas as campanhas que denigrem o outro genitor, há a possibilidade de reversão, pois o convívio entre a criança e o genitor alienado, ainda podem ser restabelecidos, seja com a ajuda de psicólogos ou mesmo com atuação do poder judiciário, como mediador do processo de reaproximação. Porém, uma vez instalada a síndrome, o processo de reversão se torna mais complexo e dificultoso, pois há casos em que os filhos preferem não ter mais contato com o outro genitor. 
Conforme se observa, as conseqüências psicológicas de uma criança que apresenta a Síndrome da Alienação Parental são drásticas. Dessa forma, observa-se que a lei 12.318/2010, não trata especificamente da Síndrome da Alienação Parental, e sim, do comportamento de Alienação Parental, ação anterior a apresentação da Síndrome.

Neste contexto, torna-se pertinente ressaltar a importância da atuação do Poder Judiciário em tomar as medidas necessárias para evitar, que a pratica da Alienação Parental apresente seus contornos mais perversos.

O caminho que está sendo encontrado para evitar a ocorrência da Alienação Parental tem sido com adoção do modelo da guarda compartilhada. Este modelo proporciona que ambos os genitores participem de forma ativa da vida da criança, cabendo aos dois as decisões sobre assuntos pertinentes como educação, saúde etc. A guarda compartilhada permite um convívio constante dos pais com seus filhos, diminuindo assim, os sentimentos de perda e rejeição que podem surgir com a mudança do ambiente familiar.

\section{CONCLUSÕES}

Conforme foi observado, o tema da Alienação Parental se apresenta ainda muito novo no mundo jurídico. Um dos caminhos possíveis de se analisar a pratica da Alienação Parental é nos casos judiciais que versam sobre a guarda e custodia dos filhos. De acordo com o trabalho realizado verificou-se que a existência de comportamentos de alienação parental, pode causar consequências desastrosas no desenvolvimento da criança e do adolescente.

Depois de propor uma introdução sobre a Alienação Parental, enfatizando os seus conceitos, o estudo passou a analisar suas consequências mais gravosas, que decorre com apresentação da Síndrome da Alienação Parental. Verifica-se, que os danos causados com apresentação da Síndrome, são severos. Assim, para evitar a ocorrência da alienação parental, têm-se adotado, nos últimos anos, o modelo de guarda compartilhada ao invés da guarda unilateral. Este modelo proporciona que ambos os genitores participem de forma ativa da vida da criança, dividindo responsabilidades que versam sobre a saúde e educação dos filhos.

Dessa forma, averígua-se que o modelo de guarda compartilhada permite um convívio mais harmônico entre a família, diminuindo os sentimentos rejeição que podem surgir com a mudança do status familiar. 


\section{REFERÊNCIAS}

BRASIL. C. N. Lei n 12.318 de 26 de agosto de 2010. Diário Oficial da União, 27 de agosto de 2010.

DIAS, M. B. Manual de Direito de Família. 5. ed. São Paulo: Revista dos Tribunais, 2009.

DIAS, M. B. SÍNDROME DA ALIENAÇÃO PARENTAL, O QUE É ISSO? In: Revista do Centro de Apoio Operacional Cível / Ministério Público do Estado do Pará, Belém. Ano 11, N.15, p. 1-15. 2009. Disponível em: <https://www2.mp.pa.gov.br/sistemas/gcsubsites/upload/25/REVISTA DO CAO CIVEL(2). > Acesso em 10.09.2015.

DINIZ, M. H. Curso de Direito Civil Brasileiro: direito de família. v. 5, 23 ed. São Paulo: Saraiva, 2008.

FIGUEIREDO, F. V.; ALEXANDRIDIS, G. Alienação Parental. São Paulo: Saraiva 20011.

FONSECA, P. M. P. C. Síndrome da Alienação Parental. In: Revista do Centro de Apoio Operacional Cível / Ministério Público do Estado do Pará, Belém. Ano 11, N.15, p. 1-15. 2009. Disponível em: <https://www2.mp.pa.gov.br/sistemas/gcsubsites/upload/25/REVISTA DO CAO CIVEL(2). > Acesso em 10.09.2015.

FREITAS, D. P.; PELLIZZARO, G. Alienação Parental: Comentários à Lei 12.318/2010. Rio de Janeiro: Forense, 2010.

GONÇALVES, C. R. Direito Civil Brasileiro: Direito de Família. Vol. VI 12a ed. Saraiva: 2015.

TRINDADE, J. Manual de Psicologia Jurídica para Operadores do Direito. Porto Alegre: Livraria do Advogado Editora, 2004. 